\title{
MODEL DEVELOPMENT FOR SURFACE ROUGHNESS PREDICTION OF AL 1050/SiCp MMCs MACHINED PARTS
}

\author{
A. M. Easa and Abeer S. Eisa \\ Production Engineering and Mechanical Design Department, Faculty of Engineering \\ Minoufiya University, Shebin Elkom, Egypt
}

\begin{abstract}

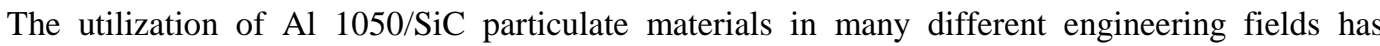
undergone a tremendous increase. Accordingly, the need for accurate machining of this type of metal matrix composites has been increased enormously. In the present research, an attempt has been made to examine the effect of cutting parameters (cutting speed, depth of cut, feed rate) and two parameters of composite reinforcement; volume fraction and particle size on the machined part surface roughness through the investigated mathematical model developed by using the results gathered from a series of milling experiments. For this purpose, the experimental were reported for five of the maintained parameters. Twenty-five workpieces were fabricated to cover these investigations. A vertical milling machine was used in machining of Al 1050 / SiCp MMCs. The surface roughness $(\mathrm{Ra})$ results were reported with different cutting parameters. The results of research indicated that ; the investigated procedure can be used to predict the surface roughness (Ra) for milling $\mathrm{Al} 1050 / \mathrm{SiCp} \mathrm{MMCs}$, the experimental results and the predicted data by developed model indicate a good correlation, the surface roughness ( $\mathrm{Ra}$ ) decreases with the increase of cutting speed up to $140 \mathrm{rpm}$, but the surface roughness increases with the increase of ; depth of cut up to $1.5 \mathrm{~mm}$, feed up to $1.25 \mathrm{~mm} / \mathrm{rev}$, volume fraction up to $25 \%$ and practical size up to $25 \mu \mathrm{m}$.Also, the use of high cutting speed $(140 \mathrm{rpm})$, depth of cut $0.25 \mathrm{~mm}$, feed $0.4 \mathrm{~mm} / \mathrm{rev}$, volume fraction $5 \%$ and practical size $7.0 \mu \mathrm{m}$ gives a good surface roughness (Ra) as compared with other values of the parameters used in this research.
\end{abstract}

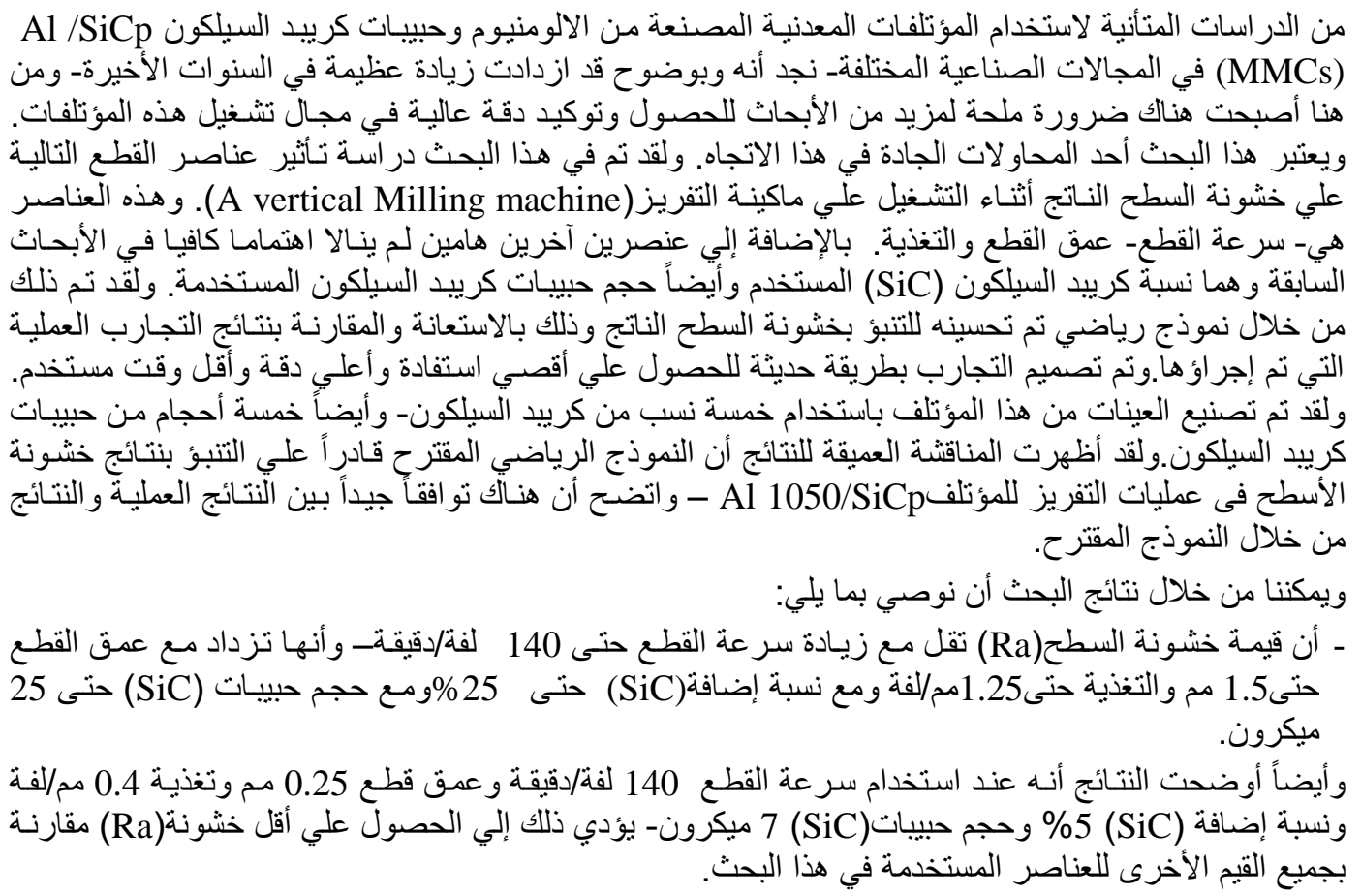

Keywords: Surface roughness, Metal matrix, Composites, ANOVA, Taguchi Technique

\section{INTRODUCTION}


Particulate metal matrix composites (PMMCs) have found wide applications in some industrial fields in which the parts are required to be light and heat resistant or wear resistant. Particularly, noncontinuously reinforced materials such as aluminum matrix composites reinforced by silicon carbide particles have become practical engineering materials [1]. End milling is the most metal removal operation encountered, it is widely used in a variety of manufacturing industrial including the aerospace and automotive sectors [2]. In machining of parts, surface quality is one of the most specified customer requirements where major indication of surface quality on machined parts is surface roughness. The quality of the surface plays a very important role in the performance of milling as a good quality milled. Surface significantly improves fatigue strength, corrosion resistance or creep life. Surface roughness also affects several functional attributes of parts, such as; contact causing surface friction, wearing light reflection, heat transmission, ability of distributing and holding a lubricant coating, or resisting fatigue [3]. There fore, the desired finish surface is usually specified and the appropriate processes are selected to reach the required quality. Surface roughness is mainly a result of process parameters such as tool geometry (edge geometry, rake angle ... etc) and cutting conditions (cutting speed, depth of cut, feed rate ... etc) $[4,5]$.

The mechanism behind the formation of surface roughness is very dynamic, complicated and process dependent It is very difficult to calculate its value through theoretical analysis. Therefore, machine operators usually use (trial and error) approaches on set-up milling machine cutting conditions in order to achieve the desired surface roughness [6]. It is obvious that, trial and error method is not effective and efficient and the achievement of a desirable value is a repetitive and empirical process that can be very time consuming. The dynamic nature and widespread usage of milling operations in practice have raised a need for seeking a systematic approach that can help to set-up milling operations in a timely manner and also to help achieve the desired surface roughness quality [7].

Using gene expression programming (GEP) [8], surface roughness prediction has been done using a few experimental data. GEP is coming from its ability to generate mathematical equations that can be easily programmed even into programming for use in monitoring of surface quality. The parameters, which are used in this study are; spindle speed, feed rate, depth of cut and Ra for CNC end milling.

In [9], the development of models based on feed forward neural networks in predicting accurately both surface roughness and tool flank wear in finish dry hard turning was presented. Neural network modes with cutting force inputs and a single output yielded better results than neural networks with two outputs, which predict surface roughness and tool wear together. In [10], 3D surface roughness prediction technique in end milling using regression analysis is investigated. From this work, regression analysis can be used trusty to find relationships between surface roughness parameters (Sa) and technological parameters (V, a, f). This work gives more realistic view of surface roughness. Also, from this work the technological parameters range plays a very important role on forming surface roughness.

In [11], the development of a response model for turning macro utilizing factorial design of experiment and response surface methodology are investigated. First order predicative model covering the cutting speed of $15-60 \mathrm{~m} / \mathrm{min}$, has been developed at $95 \%$ confidence interval. The surface roughness model is developed in terms of cutting speed, rate of feeds and depth of cut. In [12],data dependent systems analysis DDS method is used to characterize the surface generation in ultra-precision machining of $\mathrm{AL} / \mathrm{SiC}$ MMCs. The metal cutting dynamics are characterized by the natural frequency, the damping ratio, and the relative contribution of the central wavelength components which make up the roughness profile of the workplace. From the experimental work and the analysis of this research, the cutting dynamics of the surface roughness possess a strong correlation with the surface generation mechanisms of MMCs. Moreover, the DDS analysis method provides an effective way to characterize quantitatively the effect of cutting phenomena such as the cut through and pulled out mechanisms on the surface generation in ultra-precision machining of AL/SiC MMCs. In [13], down milling machining process of Alumic-79 is modeled using the adaptive neuron fuzzy inference system (ANFIS) to predict the effect of machining variables (spindle speed, feed rate, depth of cut and number of flutes) on the surface roughness .Optimum surface roughness is achieved for four flutes at the specific machining variables.

In the present research, a mathematical model has been developed to predict the surface roughness of machined $\mathrm{Al} / \mathrm{SiCp}$ workpiece using response surface method( RSM). Five parameters are used in this work; cutting speed, depth of cut, feed rate, fraction ratio and particle size.

\section{EXPERIMENTAL WORK}

\subsection{Design of Experiment}

The present investigation has been planned for achieving the desired prediction model of surface roughness on $\mathrm{Al} 1050 / \mathrm{SiCp}$ composite machined parts. In order to achieve the desired aim, the investigations are planned in the following sequence; identifying parameters which are having influence on 
surface roughness, conducting the experiments as per the design matrix, developing the experimental design matrix, developing the mathematical model, calculating the coefficients of model and testing the significance of the coefficients, checking the adequacy of the developed model and analyzing the effect of different parameters on surface roughness.

During machining, many factors affect the surface roughness. Feed rate and cutting speed are the important factors which affect the quality of surface roughness [14]. Depth of cut is another important factor affecting the finish of machined surfaces. It is found that, surface roughness and profiles are highly dependent on the depth of cut [15]. Therefore, the independently controllable predominal machining parameters that are having large influences on surface roughness of $\mathrm{Al} / \mathrm{SiC}$ (MMC) specimens have been identified. They are; i) cutting speed; ii) feed rate, iii) depth of cut. Also, in this work volume fraction ratio and particle size are investigated. The chosen parameters, units and their levels chosen are summarized in Table (1).

\subsection{Conducting the Experiment}

\subsubsection{Matrix material}

Aluminum alloy 1050 is used in this work. This alloy is popular grade of aluminum for general applications where moderate strength is required. $\mathrm{Al}$ 1050 is known for excellent corrosion resistance, high ductility and highly reflective finish. The physical and mechanical properties of $\mathrm{Al} 1050$ are listed in Table (2). And also the chemical composition of $\mathrm{Al} 1050$ is listed in Table (3).

\subsubsection{Reinforcement materials}

Silicon carbide particulate $(\mathrm{SiCp})$ is used as reinforcement material in this work. The physical and mechanical properties of $\mathrm{SiC}$ are listed in Table (4) and chemical composition is listed in Table (5).

\section{CASTING OF SPECIMENS}

The following steps are used for fabrication the Al 1050/SiCp composites;

1- Determination the volume of Al 1050 alloy depending on the dimensions of specimen and the quantity,

2- Determinations the volume of silicon carbide ( $\mathrm{SiCp})$, these volumes are related to the ratios of volume fraction used in this research. These ratios are; 5, 10, 15, 20 and $25 \%$.

3- The particle size which used are; $7,10,14$, 20 and $25 \mu \mathrm{m}$

4- The reo-cast method is used for fabricating the specimens.

\section{MACHINING OF SPECIMENS}

Four teeth, ten-millimeter diameter, HSS end mill cutting tool is used. A new cutter is used after each of experiment. The cutter is used for only five pieces of specimens to eliminate tools wear effect at the dry cutting. Therefore, five new cutters are used in this work, also, five of; cutting speed, feed rate, and depth of cut are used in these investigations.

The machining operations are carried out as per the condition given by the design matrix (Table 6) at random to avoid systematic errors.

Table 1, The levels used of identified factors

\begin{tabular}{|l|l|l|l|l|l|l|l|}
\hline \multirow{2}{*}{ Parameters } & \multicolumn{5}{|c|}{ Levels used } & \multicolumn{3}{|c|}{$\begin{array}{l}\text { Range of } \\
\text { par, }\end{array}$} \\
\cline { 2 - 8 } & $(-2)$ & $(-1)$ & $(0)$ & $(+1)$ & $(+2)$ & Min & Max \\
\hline $\begin{array}{l}\text { Cutting } \\
\text { speed, rpm }\end{array}$ & 28 & 45 & 90 & 112 & 140 & 28 & 140 \\
\hline $\begin{array}{l}\text { Depth of } \\
\text { cut, mm }\end{array}$ & 0.25 & 0.5 & 1.0 & 1.25 & 1.5 & 0.25 & 1.5 \\
\hline $\begin{array}{l}\text { Feed, } \\
\text { mm/rev }\end{array}$ & 0.4 & 0.6 & 0.8 & 1.0 & 1.25 & 0.40 & 1.25 \\
\hline $\begin{array}{l}\text { Volume } \\
\text { fraction \% }\end{array}$ & 5 & 10 & 15 & 20 & 25 & 5 & 25 \\
\hline $\begin{array}{l}\text { Particle } \\
\text { size } \mu \mathrm{m}\end{array}$ & 7 & 10 & 14 & 20 & 25 & 7 & 25 \\
\hline
\end{tabular}

Table 2, Physical and mechanical properties of $\mathrm{Al}$ 1050

\begin{tabular}{|l|l|}
\hline \multicolumn{1}{|c|}{ Property } & \multicolumn{1}{c|}{ Value } \\
\hline Proof stress $-2 \%$ & $35 \mathrm{MPa}$ \\
\hline Tensile strength & $80 \mathrm{MPa}$ \\
\hline Shear strength & $50 \mathrm{MPa}$ \\
\hline Elongation, A5 & $42 \%$ \\
\hline Hardness Vickers & $20 \mathrm{HV}$ \\
\hline Density & $2.71 \mathrm{gm} / \mathrm{cm}^{3}$ \\
\hline Melting point & $650^{\circ} \mathrm{c}$ \\
\hline Modulus of elasticity & $71 \mathrm{GPa}$ \\
\hline Electrical resistivity & $0.0282 \times 10^{-6}-\Omega \mathrm{m}$ \\
\hline Thermal conductivity & $222 \mathrm{w} / \mathrm{m} . \mathrm{k}$ \\
\hline Thermal expansion & $24 \times 10^{-6} / \mathrm{k}$ \\
\hline
\end{tabular}

Table 3, Chemical composition of Al 1050

\begin{tabular}{|c|c|}
\hline Element & \% Present \\
\hline \hline $\mathrm{Cu}$ & $0.05 \%$ \\
\hline $\mathrm{Mg}$ & $0.05 \%$ \\
\hline $\mathrm{Si}$ & $0.25 \%$ \\
\hline $\mathrm{Fe}$ & $0.4 \%$ \\
\hline $\mathrm{Mn}$ & $0.05 \%$ \\
\hline $\mathrm{Zn}$ & $0.07 \%$ \\
\hline $\mathrm{Ti}$ & $0.05 \%$ \\
\hline $\mathrm{Al}$ & Balance \\
\hline
\end{tabular}

Table 4, Physical and mechanical properties of SiC 


\begin{tabular}{|l|l|}
\hline Property & Value \\
\hline Density & $3.1 \mathrm{gm} / \mathrm{cc}$ \\
\hline Porosity & $0.0 \%$ \\
\hline Flexural strength & $550 \mathrm{MPa}$ \\
\hline Elastic modulus & $410 \mathrm{GPa}$ \\
\hline Poisons ratio & 0.14 \\
\hline Compressive strength & $3900 \mathrm{MPa}$ \\
\hline Hardness & 2800 \\
\hline Fracture toughness & $4.6 \mathrm{MPa}$ \\
\hline Max use temperature $(\mathrm{no}-\mathrm{load})$ & $1650{ }^{\circ} \mathrm{c}$ \\
\hline Thermal conductivity & $120 \mathrm{w} / \mathrm{m} .{ }^{\circ} \mathrm{k}$ \\
\hline
\end{tabular}

\section{SURFACE ROUGHNESS MEASUREMENT}

The machined parts are prepared accurately for measurements. The instrument which used is SJ20ip. After measuring operations, the results are tabulated for every specimen and classified into groups related to the following parameters 1) volume fraction, 2) particle size, 3) cutting speeds, 4) depth of cut, and 5) feed rate.

Table 5, Chemical composition of SiC

\begin{tabular}{|c|c|c|c|c|c|c|}
\hline $\begin{array}{l}\text { Normal abrasive } \\
\text { practical size range } \\
(\mu \mathrm{m})\end{array}$ & $\begin{array}{c}1180 \sim 1000 \\
\text { to } \\
180 \sim 150\end{array}$ & $\begin{array}{c}150 \sim 125 \\
\text { to } \\
90 \sim 63\end{array}$ & $75-53$ & $\begin{array}{l}63 \sim 50 \\
\text { to } \\
20 \sim 14\end{array}$ & $\begin{array}{c}14 \sim 10 \\
\text { to } \\
10 \sim 7\end{array}$ & $\begin{array}{l}7 \sim 5 \\
\text { to } \\
5 \sim 3.5\end{array}$ \\
\hline $\begin{array}{l}\text { Chemical } \\
\text { composition } \% \quad \text { (by } \\
\text { weight) }\end{array}$ & $\geq 99.0 \%$ & $\geq 98.5 \%$ & $\geq 97.5 \%$ & $\geq 97.0 \%$ & $\geq 95.5 \%$ & $\geq 94.0 \%$ \\
\hline
\end{tabular}

Table 6, Design matrix at random to a void systematic error

\begin{tabular}{|c|c|c|c|c|c|c|}
\hline $\begin{array}{c}\text { Code } \\
\text { No. }\end{array}$ & $\begin{array}{c}\text { Cutting } \\
\text { speed } \\
\text { rpm } \\
(V)\end{array}$ & $\begin{array}{c}\text { Depth } \\
\text { of cut, } \\
\text { mm } \\
\text { (d) }\end{array}$ & $\begin{array}{c}\text { Feed } \\
\text { rate } \\
\mathrm{mm} / \mathrm{rev} \\
(f)\end{array}$ & $\begin{array}{c}\text { Vol. } \\
\text { fraction\% } \\
\text { age }(V f)\end{array}$ & $\begin{array}{c}\text { Particle } \\
\text { size } \mu m \\
\quad(p s)\end{array}$ & $\begin{array}{c}R a \\
\mu m\end{array}$ \\
\hline 1 & 28 & 0.25 & 0.40 & 5.0 & 7.0 & 2.1 \\
\hline 2 & 45 & 0.25 & 0.40 & 5.0 & 7.0 & 1.9 \\
\hline 3 & 90 & 0.25 & 0.40 & 5.0 & 7.0 & 1.3 \\
\hline 4 & 112 & 0.25 & 0.40 & 5.0 & 7.0 & 1.15 \\
\hline 5 & 140 & 0.25 & 0.40 & 5.0 & 7.0 & 0.6 \\
\hline 1 & 28 & 0.50 & 0.60 & 10 & 10 & 2.5 \\
\hline 2 & 45 & 0.50 & 0.60 & 10 & 10 & 2.2 \\
\hline 3 & 90 & 0.50 & 0.60 & 10 & 10 & 1.5 \\
\hline 4 & 112 & 0.50 & 0.60 & 10 & 10 & 1.2 \\
\hline 5 & 114 & 0.50 & 0.60 & 10 & 10 & 0.8 \\
\hline 1 & 28 & 1.0 & 0.8 & 15 & 14 & 4.0 \\
\hline 2 & 45 & 1.0 & 0.8 & 15 & 14 & 3.0 \\
\hline 3 & 90 & 1.0 & 0.8 & 15 & 14 & 2.5 \\
\hline 4 & 112 & 1.0 & 0.8 & 15 & 14 & 2.0 \\
\hline 5 & 140 & 1.0 & 0.8 & 15 & 14 & 1.5 \\
\hline 1 & 28 & 1.25 & 1.0 & 20 & 20 & 4.5 \\
\hline 2 & 45 & 1.25 & 1.0 & 20 & 20 & 3.9 \\
\hline 3 & 90 & 1.25 & 1.0 & 20 & 20 & 3.0 \\
\hline 4 & 112 & 1.25 & 1.0 & 20 & 20 & 2.6 \\
\hline 5 & 140 & 1.25 & 1.0 & 20 & 20 & 2.2 \\
\hline 1 & 28 & 1.5 & 1.25 & 25 & 25 & 5.2 \\
\hline 2 & 45 & 1.5 & 1.25 & 25 & 25 & 4.0 \\
\hline 3 & 90 & 1.5 & 1.25 & 25 & 25 & 3.5 \\
\hline 4 & 112 & 1.5 & 1.25 & 25 & 25 & 3.0 \\
\hline 5 & 140 & 1.5 & 1.25 & 25 & 25 & 2.6 \\
\hline
\end{tabular}




\section{DEVELOPING THE EXPERIMENTAL DESIGN MATRIX}

Central composite rotatable designs of second order have been found to be the most efficient tool in response surface model (RSM) to establish the mathematical relation of the response surface using the smallest possible number of experiments without loosing its accuracy. The identified factors, lower and upper limits are discussed before and shown in Table (1). Table (7) shows the 32 set of coded conditions used from the control composite rotatable design matrix. It comprises of full replication of $2^{5}=32$ factorial design.

All the chosen variables at intermediate level (0) constitute the center points and the combination each of the variable at either its lowest $(-2)$ or highest $(+2)$ with the other three variables of the intermediate levels constitute the star points.
Thus, the 32 experimental runs allowed the estimation of the linear, quadratic and two ways interactive offers of the variables on the surface roughness. The method of designing such a matrix is dealt in [11]. For the convenience of recording and processing the experimental data, the upper and lower levels of the parameters are coded as $(+2)$ and $(-2)$. The coded value of any intermediated levels can be calculated by using the following expression;

$$
X i=\frac{\left[2 x-\left(x_{\max }+x_{\min }\right)\right]}{\left[\frac{x_{\max }-x_{\min }}{2}\right]}
$$

Where, $x_{\max }$ is the upper level of the parameter, $\mathrm{x}_{\min }$ is the lower level of the parameter and $\mathrm{xi}$ is the required coded values of the parameter of any value of $x$ from $x_{\min }$ to $x_{\max }$.

Table 7, Layout of central composite rotatable design matrix.

\begin{tabular}{|c|c|c|c|c|c|c|c|c|c|c|c|c|c|c|c|c|c|c|c|c|}
\hline$S$ & $A$ & $B$ & $C$ & $D$ & $E$ & $A^{2}$ & $B^{2}$ & $C^{2}$ & $D^{2}$ & $E^{2}$ & $A B$ & $A C$ & $A D$ & $A E$ & $B C$ & $B D$ & $B E$ & $C D$ & $C E$ & $D E$ \\
\hline 1 & -1 & -1 & -1 & 1 & 1 & 1 & 1 & 1 & 1 & 1 & 1 & 1 & 1 & -1 & 1 & 1 & -1 & 1 & -1 & -1 \\
\hline 2 & 1 & -1 & -1 & -1 & -1 & 1 & 1 & 1 & 1 & 1 & -1 & -1 & -1 & -1 & 1 & 1 & 1 & 1 & 1 & 1 \\
\hline 3 & -1 & -1 & -1 & -1 & -1 & 1 & 1 & 1 & 1 & 1 & -1 & +1 & 1 & 1 & -1 & -1 & -1 & 1 & 1 & 1 \\
\hline 4 & 1 & 1 & -1 & $\begin{array}{l}-1 \\
\end{array}$ & 1 & 1 & 1 & 1 & 1 & 1 & 1 & -1 & $\begin{array}{l}-1 \\
\end{array}$ & 1 & -1 & -1 & 1 & 1 & -1 & -1 \\
\hline 5 & -1 & -1 & 1 & -1 & -1 & 1 & 1 & 1 & 1 & 1 & 1 & -1 & 1 & -1 & -1 & 1 & 1 & -1 & -1 & 1 \\
\hline 6 & 1 & -1 & 1 & -1 & -1 & 1 & 1 & 1 & 1 & 1 & -1 & 1 & -1 & 1 & -1 & 1 & 1 & -1 & -1 & 1 \\
\hline 7 & -1 & 1 & 1 & -1 & 1 & 1 & 1 & 1 & 1 & 1 & -1 & -1 & 1 & -1 & 1 & -1 & 1 & -1 & 1 & -1 \\
\hline 8 & 1 & 1 & 1 & 1 & -1 & 1 & 1 & 1 & 1 & 1 & 1 & 1 & 1 & 1 & 1 & 1 & -1 & 1 & 1 & -1 \\
\hline 9 & -1 & -1 & -1 & 1 & -1 & 1 & 1 & 1 & 1 & 1 & 1 & 1 & -1 & -1 & 1 & -1 & -1 & -1 & 1 & -1 \\
\hline 10 & 1 & -1 & -1 & 1 & 1 & 1 & 1 & 1 & 1 & 1 & -1 & -1 & 1 & 1 & 1 & -1 & -1 & -1 & -1 & 1 \\
\hline 11 & -1 & 1 & -1 & 1 & -1 & 1 & 1 & 1 & 1 & 1 & -1 & 1 & -1 & -1 & -1 & 1 & -1 & -1 & 1 & -1 \\
\hline 12 & 1 & 1 & -1 & 1 & 1 & 1 & 1 & 1 & 1 & 1 & 1 & -1 & 1 & 1 & -1 & 1 & 1 & -1 & -1 & 1 \\
\hline 13 & -1 & -1 & 1 & 1 & -1 & 1 & 1 & 1 & 1 & 1 & 1 & -1 & -1 & 1 & -1 & -1 & 1 & 1 & -1 & -1 \\
\hline 14 & 1 & -1 & 1 & 1 & -1 & 1 & 1 & 1 & 1 & -1 & 1 & -1 & 1 & -1 & 1 & -1 & 1 & 1 & -1 & -1 \\
\hline 15 & -1 & 1 & 1 & 1 & 1 & 1 & 1 & 1 & 1 & -1 & -1 & -1 & -1 & 1 & 1 & 1 & 1 & 1 & 1 & 1 \\
\hline 16 & 1 & 1 & 1 & 1 & 1 & 1 & 1 & 1 & 1 & 1 & 1 & 1 & 1 & 1 & 1 & 1 & 1 & 1 & 1 & 1 \\
\hline 17 & -2 & 0 & 0 & 0 & 0 & 4 & 0 & 0 & 0 & 0 & 0 & 0 & 0 & 0 & 0 & 0 & 0 & 0 & 0 & 0 \\
\hline 18 & 2 & 0 & 0 & 0 & 0 & 4 & 0 & 0 & 0 & 0 & 0 & 0 & 0 & 0 & 0 & 0 & 0 & 0 & 0 & 0 \\
\hline 19 & 0 & -2 & 0 & 0 & 0 & 0 & 4 & 0 & 0 & 0 & 0 & 0 & 0 & 0 & 0 & 0 & 0 & 0 & 0 & 0 \\
\hline 20 & 0 & 2 & 0 & 0 & 0 & 0 & 4 & 0 & 0 & 0 & 0 & 0 & 0 & 0 & 0 & 0 & 0 & 0 & 0 & 0 \\
\hline 21 & 0 & 0 & -2 & 0 & 0 & 0 & 0 & 4 & 0 & 0 & 0 & 0 & 0 & 0 & 0 & 0 & 0 & 0 & 0 & 0 \\
\hline 22 & 0 & 0 & 2 & 0 & 0 & 0 & 0 & 4 & 0 & 0 & 0 & 0 & 0 & 0 & 0 & 0 & 0 & 0 & 0 & 0 \\
\hline 23 & 0 & 0 & 0 & -2 & 0 & 0 & 0 & 0 & 4 & 0 & 0 & 0 & 0 & 0 & 0 & 0 & 0 & 0 & 0 & 0 \\
\hline 24 & 0 & 0 & 0 & 2 & 0 & 0 & 0 & 0 & 4 & 0 & 0 & 0 & 0 & 0 & 0 & 0 & 0 & 0 & 0 & 0 \\
\hline 25 & 0 & 0 & 0 & 0 & -2 & 0 & 0 & 0 & 0 & 4 & 0 & 0 & 0 & 0 & 0 & 0 & 0 & 0 & 0 & 0 \\
\hline 26 & 0 & 0 & 0 & 0 & 2 & 0 & 0 & 0 & 0 & 4 & 0 & 0 & 0 & 0 & 0 & 0 & 0 & 0 & 0 & 0 \\
\hline 27 & 0 & 0 & 0 & 0 & 2 & 0 & 0 & 0 & 0 & 4 & 0 & 0 & 0 & 0 & 0 & 0 & 0 & 0 & 0 & 0 \\
\hline 28 & 0 & 0 & 0 & 0 & 0 & 0 & 0 & 0 & 0 & 0 & 0 & 0 & 0 & 0 & 0 & 0 & 0 & 0 & 0 & 0 \\
\hline 29 & 0 & 0 & 0 & 0 & 0 & 0 & 0 & 0 & 0 & 0 & 0 & 0 & 0 & 0 & 0 & 0 & 0 & 0 & 0 & 0 \\
\hline 30 & 0 & 0 & 0 & 0 & 0 & 0 & 0 & 0 & 0 & 0 & 0 & 0 & 0 & 0 & 0 & 0 & 0 & 0 & 0 & 0 \\
\hline 31 & 0 & 0 & 0 & 0 & 0 & 0 & 0 & 0 & 0 & 0 & 0 & 0 & 0 & 0 & 0 & 0 & 0 & 0 & 0 & 0 \\
\hline 32 & 0 & 0 & 0 & 0 & 0 & 0 & 0 & 0 & 0 & 0 & 0 & 0 & 0 & 0 & 0 & 0 & 0 & 0 & 0 & 0 \\
\hline
\end{tabular}




\section{DEVELOPING THE MODEL}

Representing the surface roughness of $\mathrm{Al} / \mathrm{SiCp}$ $(\mathrm{MMC})(\mathrm{Ra})$, the response function can be expressed as:

$$
\mathrm{Ra}=\mathrm{f}(\mathrm{A}, \mathrm{B}, \mathrm{C}, \mathrm{D}, \mathrm{E})
$$

The chosen model is a second-degree response surface and can be expressed as follows;

$\mathrm{Ra}=\mathrm{Co}+\mathrm{C}_{1}(\mathrm{~A})+\mathrm{C}_{2}(\mathrm{~B})+\mathrm{C}_{3}(\mathrm{C})+\mathrm{C}_{4}(\mathrm{D})+$ $\mathrm{C}_{5}(\mathrm{E})+\mathrm{C}_{6}(\mathrm{AB})+\mathrm{C}_{7}(\mathrm{AC})+\mathrm{C}_{8}(\mathrm{AD})+\mathrm{C}_{9}(\mathrm{AE})+$ $\mathrm{C}_{10}(\mathrm{BC})+\mathrm{C}_{11}(\mathrm{BD})+\mathrm{C}_{12}(\mathrm{BE})+\mathrm{C}_{13}(\mathrm{CD})+\mathrm{C}_{14}$ $(\mathrm{CE})+\mathrm{C}_{15}(\mathrm{DE})+\mathrm{C}_{16}\left(\mathrm{~A}^{2}\right)+\mathrm{C}_{17}\left(\mathrm{~B}^{2}\right)+\mathrm{C}_{18}\left(\mathrm{C}^{2}\right)+$ $\mathrm{C}_{19}\left(\mathrm{D}^{2}\right)+\mathrm{C}_{20}\left(\mathrm{E}^{2}\right)$

The values of the coefficients have been calculated and after determining the significant coefficients, the final model is developed in coded values and is given as follows:

\section{Surface roughness $(\mathrm{Ra})=$}

$-4.506+0.065(\mathrm{~A})+4.56(\mathrm{~B})-2.07(\mathrm{C})-0.005$ (D) $-0.63(\mathrm{E})-0.008(\mathrm{AB})-0.004(\mathrm{AC})-0.001$ $(\mathrm{AE})+0.183(\mathrm{BC})+0.312(\mathrm{BP})-0.312(\mathrm{CD})-0.17$ $(\mathrm{CE})-0.039(\mathrm{CE})-0.008(\mathrm{DE})-4.78\left(\mathrm{~B}^{2}\right)-0.358$ $\left(C^{2}\right)-0.004\left(E^{2}\right)$

\section{CHECKING THE ADEQUACY OF THE DEVELOPED MODEL}

By using the analysis of variance technique, the adequacy of the model is checked. As per this technique, if the calculated value $F$ ratio of the developed model does not exceed the standard tabulated value of ratio for a desired level of confidence, then the model is considered to be adequate within the confidence limit. In Table (8), ANOVA test results are presented. The experimental results and predicated data are presented in Table (9) and plotted as shown in Fig. 1.

Table 8, Analysis of variance for surface roughness

\begin{tabular}{|c|c|c|c|c|c|c|}
\hline Source & DF & $\begin{array}{c}\text { SEQ } \\
\text { SS }\end{array}$ & Adj SS & Adj MS & $\begin{array}{c}\boldsymbol{F} \text { - } \\
\text { ratio }\end{array}$ & P\% \\
\hline Regression & 20 & 21.939 & 21.939 & 1.0969 & 0.71 & 75 \\
\hline Linear & 5 & 9.323 & 7.757 & 1.5513 & 1.01 & 4.5 \\
\hline Square & 5 & 5.421 & 4.913 & 0.9832 & 0.64 & 6.7 \\
\hline Interaction & 10 & 7.195 & 7.195 & 0.7195 & 0.47 & 8.8 \\
\hline $\begin{array}{c}\text { Residual } \\
\text { error }\end{array}$ & 11 & 16.921 & 16.921 & 1.5383 & & \\
\hline Lack of fit & 4 & 12.316 & 12.316 & 3.0790 & 4.68 & 3.7 \\
\hline Pure error & 7 & 4.605 & 4.605 & 0.6579 & & \\
\hline Total & 31 & 38.860 & & & & 100 \\
\hline
\end{tabular}

Table 9, Experimental and predicted results of surface roughness

\begin{tabular}{||l|l||}
\hline Experimental & Predicted \\
\hline 2.1 & 2.35 \\
\hline 1.9 & 1.89 \\
\hline 1.3 & 1.4 \\
\hline 1.15 & 1.14 \\
\hline 0.6 & 0.69 \\
\hline 2.5 & 2.05 \\
\hline 2.2 & 2.83 \\
\hline 1.5 & 1.53 \\
\hline 1.2 & 1.31 \\
\hline 0.8 & 0.79 \\
\hline 4 & 3.8 \\
\hline 3 & 3.1 \\
\hline 2.5 & 2.05 \\
\hline 2 & 2 \\
\hline 1.5 & 1.41 \\
\hline 4.5 & 4.64 \\
\hline 3.9 & 3.81 \\
\hline 3 & 2.98 \\
\hline 2.6 & 2.62 \\
\hline 2.2 & 2.20 \\
\hline 5.2 & 5.32 \\
\hline 4 & 3.92 \\
\hline 3.5 & 3.41 \\
\hline 3 & 3.01 \\
\hline 2.6 & 2.65 \\
\hline
\end{tabular}

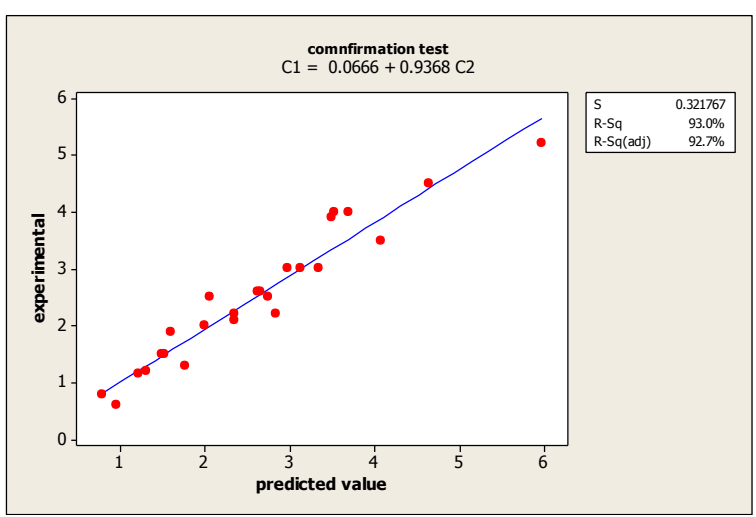

Fig. 1 The correlation between experimental and predicated results

\section{DISCUSSIONS}

\subsection{Microstructure of $\mathrm{Al} / \mathrm{SiCp}$ MMCs}

Figures 2 to 11 show the microstructures of the composites with 5,10,15,20 and $25 \%$ of volume fraction of $\mathrm{SiC}$ particles reinforcement. From these figures, it can be seen that, for all ratios of fraction, the $\mathrm{SiC}$ particles are distributed uniformly in the $\mathrm{Al}$ 1050 matrix. Pores generally co- exist with the $\mathrm{SiC}$ particles, which indicate that, the interfacial cohesion between the $\mathrm{SiC}$ particles and matrix is relatively weak. 


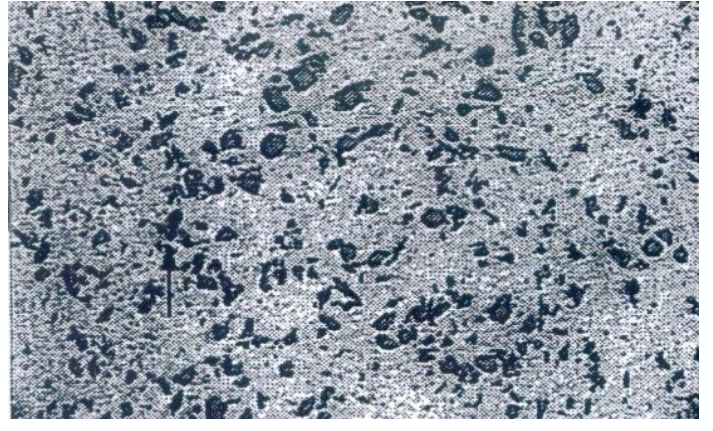

Fig. 2 Microstructure of Al $1050 / \mathrm{SiCp}$ composite $\left(\mathrm{V}_{\mathrm{f}}=5 \%, \mathrm{P}_{\mathrm{S}}=7 \mu \mathrm{m}\right),(\mathrm{X} 200)$

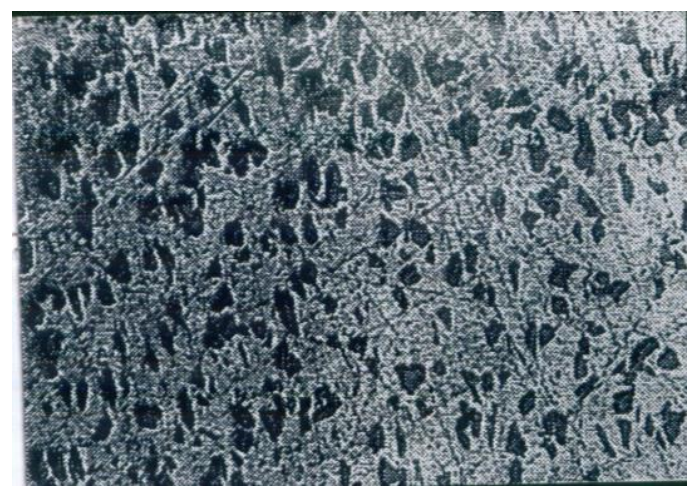

Fig. 3 Microstructure of Al $1050 / \mathrm{SiCp}$ composite

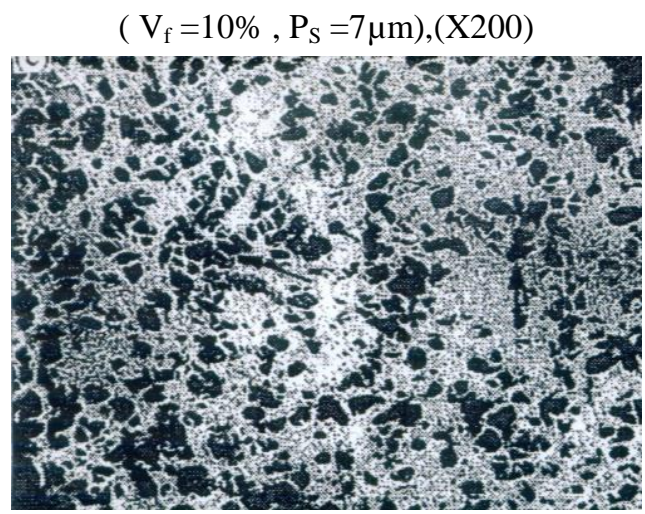

Fig. 4 Microstructure of $\mathrm{Al} 1050 / \mathrm{SiCp}$ composite $\left(\mathrm{V}_{\mathrm{f}}=15 \%, \mathrm{P}_{\mathrm{S}}=7 \mu \mathrm{m}\right),(\mathrm{X} 200)$

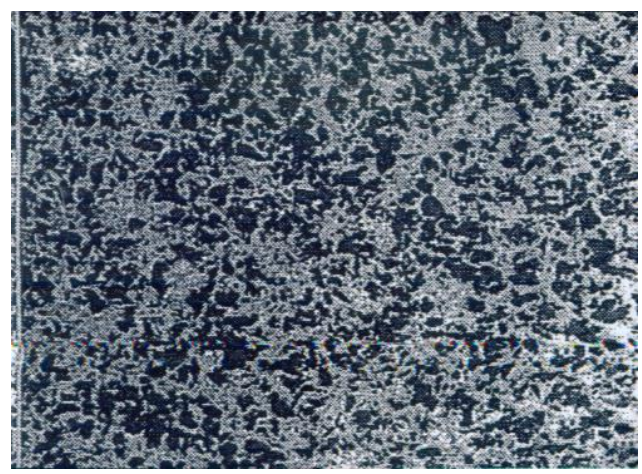

Fig. 5 Microstructure of Al $1050 / \mathrm{SiCp}$ composite $\left(\mathrm{V}_{\mathrm{f}}=20 \%, \mathrm{P}_{\mathrm{S}}=7 \mu \mathrm{m}\right),(\mathrm{X} 200)$

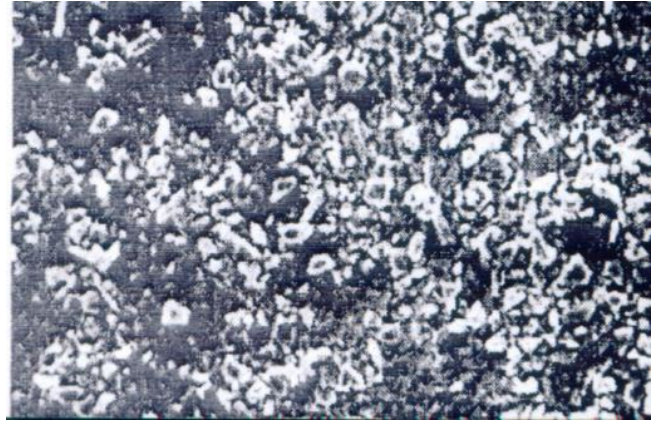

Fig. 6 Microstructure of $\mathrm{Al} 1050 / \mathrm{SiCp}$ composite

$$
\left(\mathrm{V}_{\mathrm{f}}=25 \%, \mathrm{P}_{\mathrm{S}}=7 \mu \mathrm{m}\right),(\mathrm{X} 200)
$$

\subsection{Microstructure of Machined Surface}

The microstructure of machined surface for $\mathrm{Al}$ 1050/SiCp MMCs reinforced with five different Vf ratios of $\mathrm{SiC}$ particles are shown in Figs 7 to 11 . From these figures, it is clear that, during machining of these composites, cracking and de bonding are typical damage mechanisms that greatly affect the integrity of produced surface. The particles pulled out by the cutter during cutting process leaved behind large pit holes, voids and craters that facilitate the formation of fatigue cracks. Sever damage to the machined surface can be generated due to high temperature gradients during the cutting process. This may be due to residual stress along with micro and macro cracks on the aluminum matrix that was plastically deformed causing severe hardness alterations and metallurgical transformations in the material of MMC. Also during cutting MMCs, the ductile aluminum matrix is subjected to high compressive stress by the cutter, leading to non homogenous plastic deformation. Subsequently, small pieces of the workpiece material adhere to the cutter and are welded firmly due to high temperature and pressure during cutting process. As the cutting progresses, the conglomeration of workpiece material becomes larger and unstable and when they shear off with the chip they create micro defects on the new surface. It is obvious that, the machined surface of aluminum matrix will be different when measured very close to or away from the $\mathrm{SiC}$ particles and proper care was taken in this regard. In addition to volume fraction ratio and particle size and the cutting parameters play a vital role in the resultant surface. The increase in cutting speed corresponds to an increase in strain, strain rate and temperature. The kinetics of plastic flow of the aluminum matrix is highly dependent on the cutting conditions. Consequently, the hardness changes are expected in the aluminum matrix due to plastic deformation and material volume changes associated with thermal gradients.

At lower cutting speeds, the heat generated is lower and higher mechanical stresses are imposed on 
the surface layer due to higher cutting forces generated. As a result, the effect of work hardening of the matrix dominates the loss of strength due to thermal softening of the matrix material. From figures 7 to 11 , the microstructure analysis revealed highly work hardened aluminum grains in the surface layer at lower cutting speed.

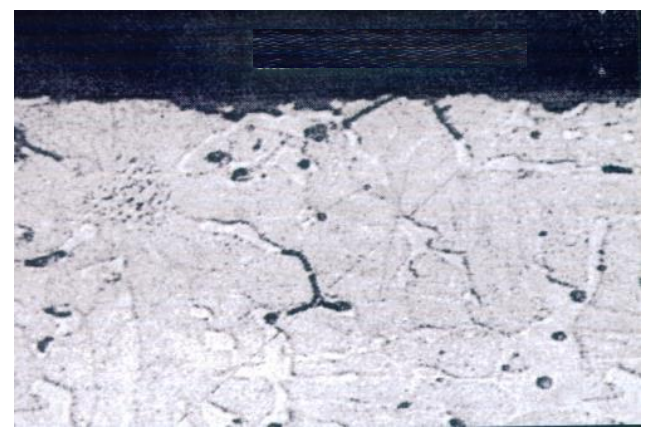

Fig. 7 Machined surface of Al 1050/15\% SiCp $\left(\mathrm{V}=28 \mathrm{rpm}, \delta=0.25 \mathrm{~mm}, \mathrm{f}=0.4 \mathrm{~mm} / \mathrm{rev}, \mathrm{V}_{\mathrm{f}}=5 \%, \mathrm{P}_{\mathrm{s}}\right.$ $=7.0 \mu \mathrm{m}),(\mathrm{X} 200)$

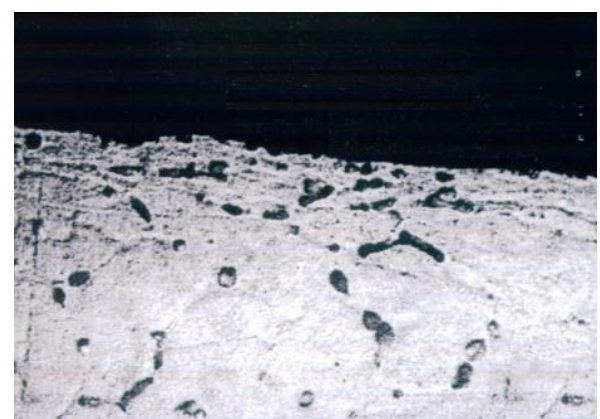

Fig. 8 Machined surface of $\mathrm{Al} 1050 \mathrm{SiC}$

$\left(\mathrm{V}=45 \mathrm{rpm}, \delta=0.5 \mathrm{~mm}, \mathrm{f}=0.6 \mathrm{~mm} / \mathrm{rev}, \mathrm{V}_{\mathrm{f}}=10 \%, \mathrm{P}_{\mathrm{s}}\right.$ $=10 \mu \mathrm{m}),(\mathrm{X} 200)$

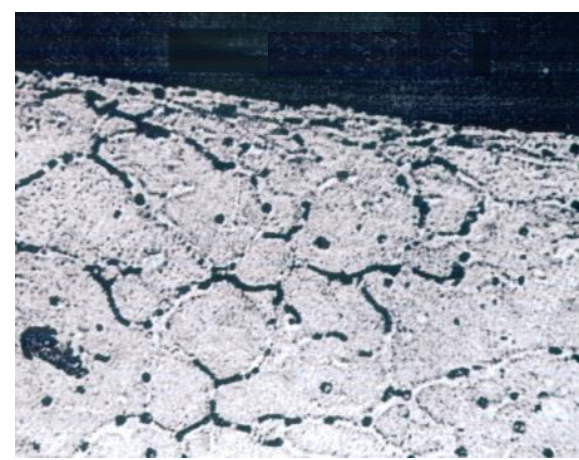

Fig. 9 Machined surface of $\mathrm{Al} 1050 / \mathrm{SiC}$

$\left(\mathrm{V}=90 \mathrm{rpm}, \delta=1 \mathrm{~mm}, \mathrm{f}=0.8 \mathrm{~mm} / \mathrm{rev}, \mathrm{V}_{\mathrm{f}}=15 \%, \mathrm{P}_{\mathrm{s}}\right.$ $=14 \mu \mathrm{m}),(\mathrm{X} 200)$

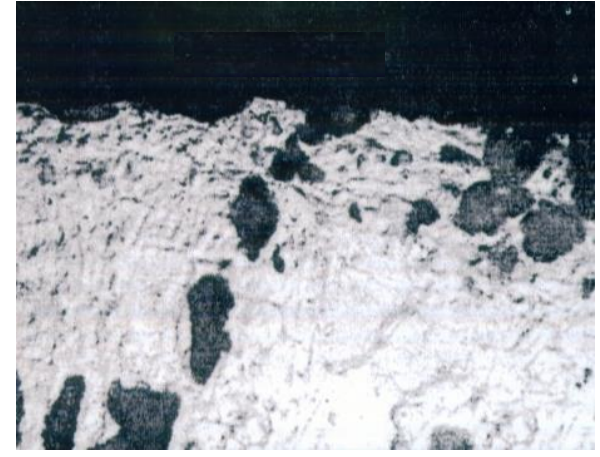

Fig. 10 Machined surface of Al1050/SiC

$\left(\mathrm{V}=112 \mathrm{rpm}, \delta=1.25 \mathrm{~mm}, \mathrm{f}=1.0 \mathrm{~mm} / \mathrm{rev}, \mathrm{V}_{\mathrm{f}}\right.$ $\left.=20 \%, \mathrm{P}_{\mathrm{s}}=20 \mu \mathrm{m}\right),(\mathrm{X} 200)$

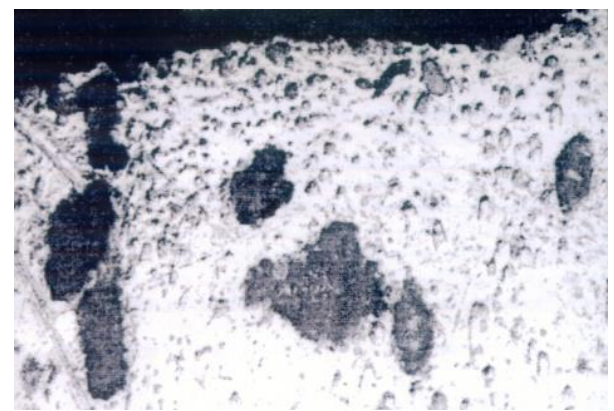

Fig. 11 Machined surface of $\mathrm{Al} 1050 / \mathrm{SiC}$

$\left(\mathrm{V}=140 \mathrm{rpm}, \delta=1.5 \mathrm{~mm}, \mathrm{f}=1.25 \mathrm{~mm} / \mathrm{rev}, \mathrm{V}_{\mathrm{f}}\right.$ $\left.=25 \%, \mathrm{P}_{\mathrm{s}}=25 \mu \mathrm{m}\right)(\mathrm{X} 200)$

\subsection{Effect of Cutting Speed on the Resultant Surface Roughness}

The cutting speeds used in the machining of $\mathrm{Al}$ 1050/ SiCp MMCs are 28, 45, 90, 112 and $140 \mathrm{rpm}$. Figure 12 shows the influence of the cutting speed on the resultant surface roughness ( $\mathrm{Ra}$ ) with five different depth of cut at fixed feed rate $0.4 \mathrm{~mm} / \mathrm{rev}$, volume fraction $5 \%$ and particle size $7.0 \mu \mathrm{m}$ )

From this Figure, it can be seen that, as cutting speed increases, Ra decreases. The increase in the depth of cut leads to increase in the roughness of machined surface. The increase in cutting speeds and decreases the depth of cut lead to better surface roughness. Normally higher cutting speed and low depth of cut is suitable for machining $\mathrm{Al} / \mathrm{SiCp}$ MMCs for getting a good surface finish, but the higher cutting speed should not be more than 140 $\mathrm{m} / \mathrm{min}$. More studies must be done for the use of cutting speed more than $140 \mathrm{rpm}$.

Figure 13 illustrates the variation of surface roughness $(\mathrm{Ra})$ with respect to different cutting speeds $(28,45,90,112$ and $140 \mathrm{rpm})$ at different feed rates $(0.4,0.6,0.8,1.0$ and 1.25 at fixed depth of cut $(0.25 \mathrm{~mm})$, particle size $(7 \mu \mathrm{m})$ and volume fraction $5 \%$ ). From this Figure the surface roughness (Ra) decreases nonlinearly with the increase of cutting speed. The surface roughness $(\mathrm{Ra})$ reduces in a proposed manner up to a cutting speed of around 
120rpm. It is clear that, the increase in feed rate leads to the increase in the surface roughness $(\mathrm{Ra})$. In the case of feed rate $(0.4 \mathrm{~mm} / \mathrm{rev})$, the values of surface roughness $(\mathrm{Ra})$ are less in all of different speeds as compared with the other values of feed rates. In this part of results, it is obvious that, the surface roughness $(\mathrm{Ra})$ increases with the increase of feed rate, but it fluctuates with different feed rates. It may be due to the imperfection and uneven distribution of $\mathrm{SiC}$ particles.

Figure 1 shows the influence of the cutting speeds with different volume fractions $(5,10,15,20$ and $25 \%$ of $\mathrm{SiCp}$ ) at depth of cut $0.25 \mathrm{~mm}$, particle size $7 \mu \mathrm{m}$ and feed rate $0.4 \mathrm{~mm} / \mathrm{rev}$. From this Figure, the surface roughness decreases nonlinearly with the increase of cutting speed. The surface roughness increases with the increase of fraction ratio. It may be due to the increase of hard particles which had a large effect on the cutter teeth. It is also may be due to un-even distribution of the $\mathrm{SiC}$ particles in manufacturing and particle pull-out during the machining operation. From this Figure, the values of (Ra) are larger than that of the previous results, it is due to the increase of fraction ratio and respectively the increase in the number of hard grains.

Figure 15 illustrates the variation of surface roughness (Ra) with respect to different cutting speed and different particles sizes $(7,10,14,20$ and $25 \mu \mathrm{m})$ at feed rate $0.4 \mathrm{~mm} / \mathrm{rev}$, depth of cut $0.25 \mathrm{~mm}$ and volume fraction $5 \%$

From this Figure, the resultant surface roughness (Ra) decreases non-linearly with the increase of cutting speed. The increase in the particle size leads to an increase in the values of surface roughness (Ra). In this Figure, the values of surface roughness (Ra) are very large as compared with the previous results. It is may be due to the increase of particle size of SiC reinforcement. Also, part of machined surface is composed of pits and voids where $\mathrm{SiC}$ is pulled out. This led to bad surface and respectively led to an increase of $(\mathrm{Ra})$.

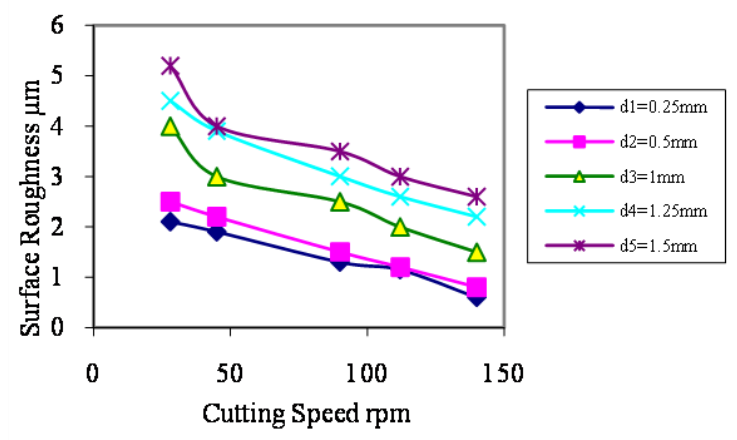

Fig. 12 Cutting speed -Ra relations with varying depth of cut at $(\mathrm{f}=0.4 \mathrm{~mm} / \mathrm{rev}, \mathrm{Ps}=7 \mu \mathrm{m}$ and $\mathrm{Vf}=$ $5 \%)$

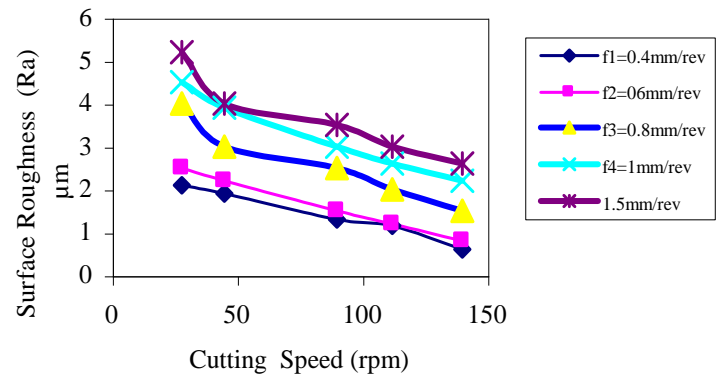

Fig. 13 Cutting speed - Ra relations with varying feed rates at $(\mathrm{d}=0.25 \mathrm{~mm}, \mathrm{Ps}=7 \mu \mathrm{m}$ and $\mathrm{Vf}=5 \%)$

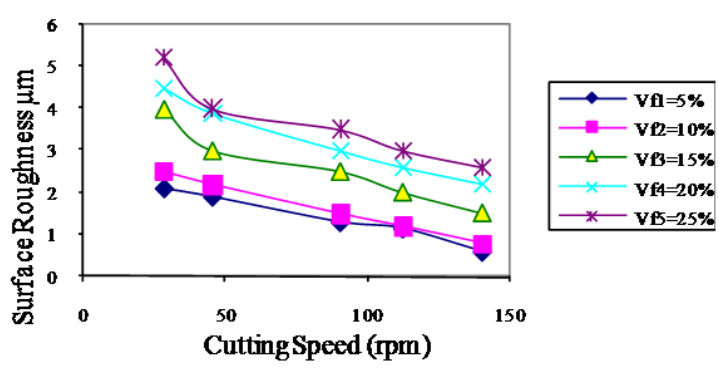

Fig. 14 Cutting speed - Ra relations with varying fraction ratio at $(\mathrm{d}=0.25 \mathrm{~mm}, \mathrm{Ps}=7 \mu \mathrm{m}$ and $\mathrm{f}=$ $0.4 \mathrm{~mm} / \mathrm{rev}$ )

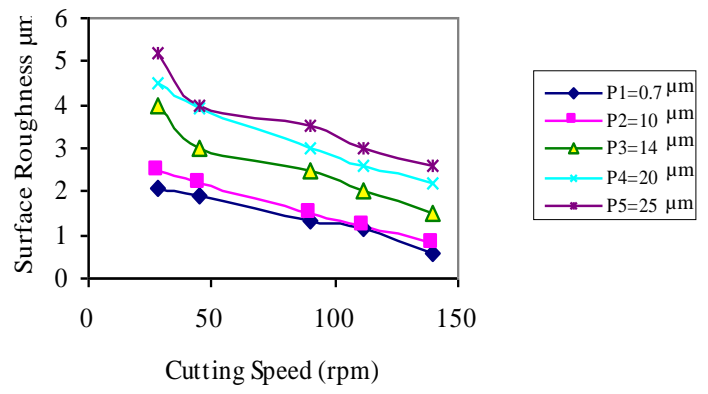

Fig. 15 Cutting speed -Ra relations with varying particle size at $(\mathrm{f}=0.4 \mathrm{~mm} / \mathrm{rev}, \mathrm{d}=0.4 \mathrm{~mm}$ and $\mathrm{Vf}=$ $5 \%$ )

\subsection{Effect of Depth of Cut on the Resultant Surface Roughness}

The depth of cut used in the machining of $\mathrm{Al}$ 1050 SiCp MMCs are, 0.25, 0.5, 1.01 .25 and 1.5 $\mathrm{mm}$. Figure 16 shows the influence of the maintained depth of cut with five cutting speeds, 28, 45, 90, 112 and $140 \mathrm{rpm}$ on the resultant surface roughness .The previous conditions of cutting are used with fixed feed rate $0.4 \mathrm{~mm} / \mathrm{rev}$, particle size $7 \mu \mathrm{m}$ and volume fraction $5 \%$. From this figure, the surface roughness increases with the increase of depth of cut for various cutting speed. But, the increase of cutting speed leads to better surface roughness. The increase of depth of cut, results dusty chips, which were easy to fall into 
the spacing between the workpiece and the flank face of the cutter. It might be cut once again or pressed into the matrix by cutting tool.

In Fig. 17 the relations between depth of cut and (Ra) are presented with varying feed rates ,0.4,0.6 $, 0.8,1.0$ and $1.5 \mathrm{~mm} / \mathrm{rev}$ and fixed values of , particle size $7 \mu \mathrm{m}$, volume fraction $5 \%$ and cutting speed 28 rpm.

From this figure, the surface roughness (Ra) increases with the increase of depth of cut. On the other hand, the increase of feed rate leads to increase of surface roughness $(\mathrm{Ra})$. In the small values of both depth of cut and feed rate, the surface roughness ( $\mathrm{Ra})$ is better as compared with the large values of the two parameters. As example, in the case of depth of cut equal $0.5 \mathrm{~mm}$ and feed rate $0.4 \mathrm{~mm} / \mathrm{rev}$, the value of $\mathrm{Ra}$ is less than $1.0 \mu \mathrm{m}$, but in the case of depth of cut equal $0.5 \mathrm{~mm}$ and feed rate $1.5 \mathrm{~mm} / \mathrm{rev}$, the $\mathrm{Ra}$ value is more than $2.0 \mu \mathrm{m}$. The increase of Ra values in the previous cases, is due to the increase in the shearing cutting part as compared with the small values of depth of cut and feed rate.

The increase in the depth of cut, results an increase of the defects in the resultant surface, such as grooves and scratches. These defects are induced by $\mathrm{SiC}$ particles which plowed through the machined surface for some distance. The surface roughness is become badly and respectively the values of $\mathrm{Ra}$ are increased.

In Fig. 18 the relations between depth of cut and $\mathrm{Ra}$ with varying volume fraction are presented. The ratios of volume fraction are, 5, 10, 15, 20 and 25\% of $\mathrm{SiC}$ particulates. These are plotted with fixed values of feed rate $0.4 \mathrm{~mm} / \mathrm{rev}$, particle size $7 \mu \mathrm{m}$ and cutting speed $28 \mathrm{rpm}$.

From this figure, it can be seen that, as depth of cut increases, Ra values are increased with all value of fractions ratio. In the range of small values of depth of cut and volume fraction, the surface roughness is better than that of any other values of the two parameters.

The increase of volume fraction from 5\% to $25 \%$ lead to dramatic increase in the resultant surface roughness from nearly, $(2 \mu \mathrm{m}$ at $0.5 \mathrm{mn}$ depth of cut to $6 \mu \mathrm{m}$ at the same depth of cut). The increase of volume fraction, hard particles of $\mathrm{SiC}$ have a large effect on the cutting edge of cutter, and some of these particles are pulled out and adopt the values of surface roughness ( $\mathrm{Ra})$ are increased.

Figure 19 illustrates the variation of surface roughness $(\mathrm{Ra})$ with respect to different depth of cut. The particle size used are, 7, 10, 14,20 and 25 $\mu \mathrm{m}$ ). Feed rate, volume fraction and cutting speed are fixed and their values are $0.4 \mathrm{~mm} / \mathrm{rev} ., 5 \%$ and 28 rpm respectively.
From this figure, the resultant surface roughness (Ra) increases with the increase of depth of cut at different particle sizes. The values of ( $\mathrm{Ra}$ ) ranged between $2.8 \mu \mathrm{m}$ nearly to $7.0 \mu \mathrm{m}$ when the particle size is changed from $7.0 \mu \mathrm{m}$ to $25 \mu \mathrm{m}$. The increase of the particle size of $\mathrm{SiC}$ reinforcement increases in the friction between the machined surface and the cutter edges. In this case, the cutter is pressed the $\mathrm{SiC}$ particles and embedded into the softer matrix. The large values of $(\mathrm{Ra})$ and the badness of surface is the result of the previous case.
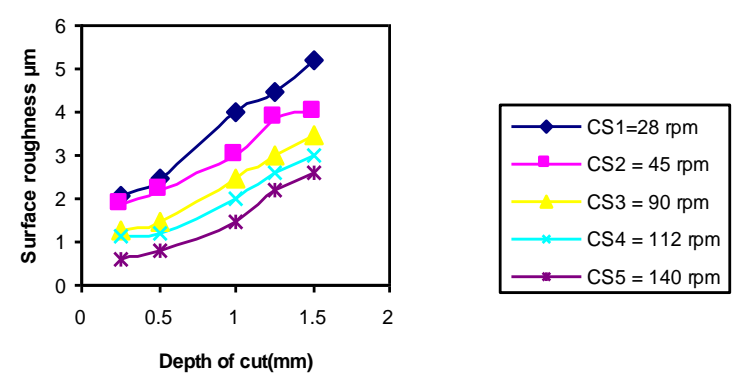

Fig. 16 Depth of cut-Ra relations with varying cutting speed at $(\mathrm{f}=0.4 \mathrm{~mm} / \mathrm{rev}, \mathrm{Ps}=7 \mu \mathrm{m}$, and $\mathrm{Vf}=$ $5 \%$ )

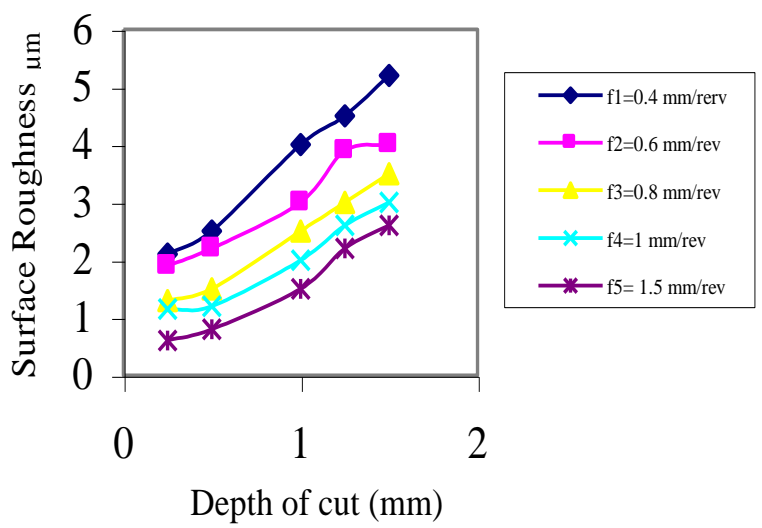

Fig. 17 Depth of cut-Ra relations with varying feed rate at $(\mathrm{Ps}=7 \mu \mathrm{m}, \mathrm{VF}=5 \%$ and cutting speed $=28 \mathrm{rpm}$ )

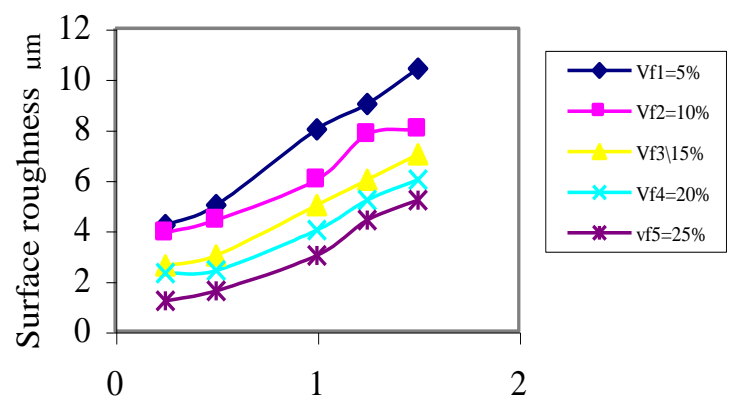

Depth of Cut (mm)

Fig. 18 Depth of cut-Ra relations with varying fraction ratios at $(\mathrm{f}=0.4 \mathrm{~mm} / \mathrm{rev}, \mathrm{Ps}=7 \mu \mathrm{m}$ and cutting speed $=28 \mathrm{rpm}$ ) 


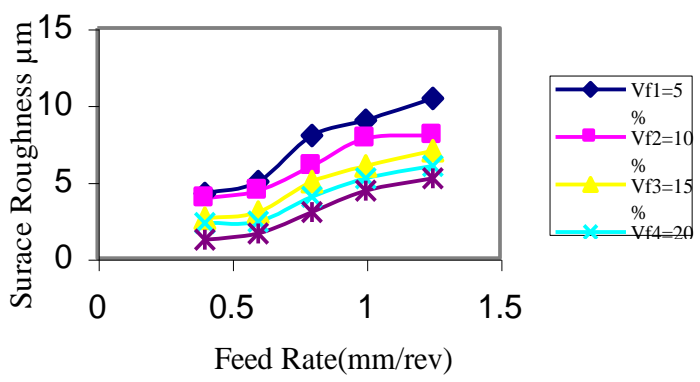

Fig. 19 Depth of cut-Ra relations with varying practical size at $(\mathrm{f}=0.4 \mathrm{~mm} / \mathrm{rev}, \mathrm{Vf}=5 \%$ and cutting speed $=28 \mathrm{rpm}$ )

\subsection{Effect of Feed Rate on the Resultant Surface Roughness}

The feed rates used in the machining of $\mathrm{Al}$ 1050/SiCp MMCs are, 0.4,0.6,0.8,1.0and 1.25 $\mathrm{mm} / \mathrm{rev}$, The fixed values of particle size, volume fraction and cutting speed are, $7 \mu \mathrm{m}, 5 \%$ and $28 \mathrm{rpm}$ respectively .

From Fig. 20 it can be seen that, as feed rate is increased the surface roughness ( $\mathrm{Ra}$ ) increase. Also, the increase in depth of cut leads to an increase in surface roughness values with various values of feed rate .In the case of smallest value of feed rate $(0.4 \mathrm{~mm} / \mathrm{rev})$ and $(0.25 \mathrm{~mm})$ depth of cut, the Ra value is nearly $0.5 \mu \mathrm{m}$, but when the feed rate is equal $1.25 \mathrm{~mm} / \mathrm{rev}$ and the same depth of cut, the (Ra) value is become more than $0.2 \mu \mathrm{m}$. It obvious that, (Ra) is increases with the increase of feed rate and depth of cut. The increase of feed rate leads to an increase the micro cracks which are formed either due to part of the SiC reinforcement detached from the matrix or due to the rotation of the $\mathrm{SiC}$ reinforcement in order to adapt the deformation of the matrix around it.

Figure 21 illustrates the variation of surface roughness $(\mathrm{Ra})$ with respect to different feed rates as mentioned in the previous figure with five cutting speeds (28.45.90.112 and $140 \mathrm{rpm})$, at fixed particle size $7 \mu \mathrm{m}$, volume fraction $5 \%$ and depth of cut $0.25 \mathrm{~mm}$.It is clear that, the surface roughness increases with the increase of feed rate and decreases with the increase of cutting speed.

At feed rate $1.0 \mathrm{~mm} / \mathrm{rev}$, rapid increase of ( $\mathrm{Ra}$ ) in all values of cutting speeds is observed. But the large value of cutting speed $140 \mathrm{~m} / \mathrm{min}$ gives a better surface roughness for all values of feed rates. The bad surface is clear in the large values of feed rates and small values of cutting speed. The increase of feed rate at lower cutting speed leads to the $\mathrm{SiC}$ reinforcement pressed into the soft matrix by the flank face of cutter. In this way, the groove created on the machined surface is wider and deeper towards the end and getting bad surface.
In Fig. 22, the relations between feed rate and surface roughness are presented with varying volume fraction $(5.10 .15 .20$ and $25 \%)$ at fixed values of particle size $7 \mu \mathrm{m}$, depth of cut $0.25 \mathrm{~mm}$ and cutting speed $28 \mathrm{rpm}$. From this Figure, the surface roughness $(\mathrm{Ra})$ increase with the different values of feed rates and all value of volume fractions. At 0.8 $\mathrm{mm} / \mathrm{rev}$ feed rate, the surface roughness is increased suddenly for all values of volume fraction. It is may be due to the fracture parts or a pulled out reinforcements fell into interspaces between the flank face and machined surface and give a bad surface finish.

Figure 23 illustrates the variation of surface roughness $(\mathrm{Ra})$ with respect to different feed rates at fixed depth of cut $0.25 \mathrm{~mm}$, volume fraction $5 \%$ and cutting speed $28 \mathrm{rpm}$. From this Figure, the resultant surface $(\mathrm{Ra})$ increases with the increase of feed rate and particle size. The increase of particle size from $7 \mu \mathrm{m}$ to $25 \mathrm{~mm}$ lead to increase in surface roughness value from $1.5 \mathrm{~mm}$ to $6.0 \mathrm{~mm}$ at feed rate equal 0.4 $\mathrm{mm} / \mathrm{rev}$. Also, the change of feed rate from 0.4 $\mathrm{mm} / \mathrm{rev}$ to the maximum value $1.25 \mathrm{~mm} / \mathrm{rev}$, leads to an dramatic increase in the values of surface roughness. From this Figure it is obvious that, the particle size plays a vital role in the resultant surface roughness. It is may be due to the increase of friction between the tooth of cutter and the particles of $\mathrm{SiC}$ reinforcement. Some of particles are sheared or pulled out, and matrix is tearing also. The fracture parts are pressed into the tearing matrix and give a bad surface roughness.

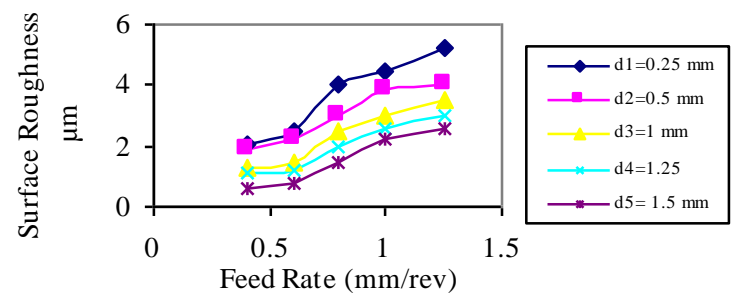

Fig. 20 Feed rate - Ra relations with varying depth of cut at $(\mathrm{Ps}=7 \mu \mathrm{m}, \mathrm{Vf}=5 \%$ and cutting speed $=28 \mathrm{rpm})$

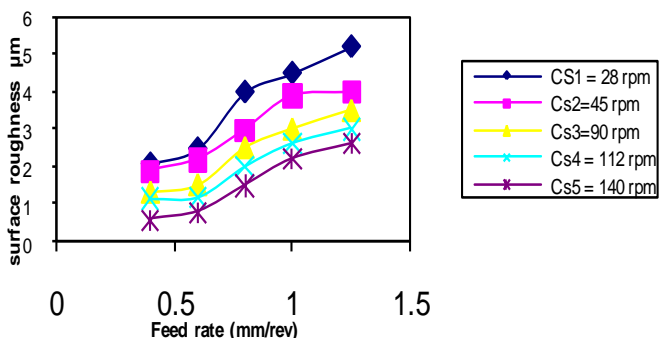

Fig. 21 Feed rate - Ra relations with varying cutting speed at $(\mathrm{Ps}=7 \mu \mathrm{m}, \mathrm{Vf}=5 \%$ and $\mathrm{d}=0.25 \mathrm{~mm})$ 


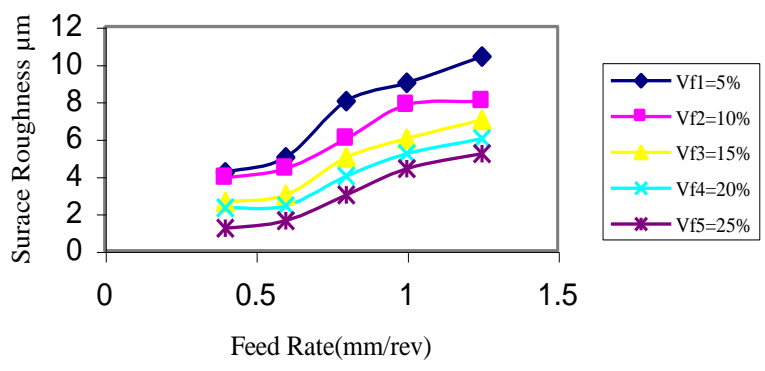

Fig. 22 Feed rate - Ra relations with varying fraction ratios at $(\mathrm{Ps}=7 \mu \mathrm{m}, \mathrm{d}=0.25 \mathrm{~mm}$ and cutting speed $=28 \mathrm{rpm}$ )

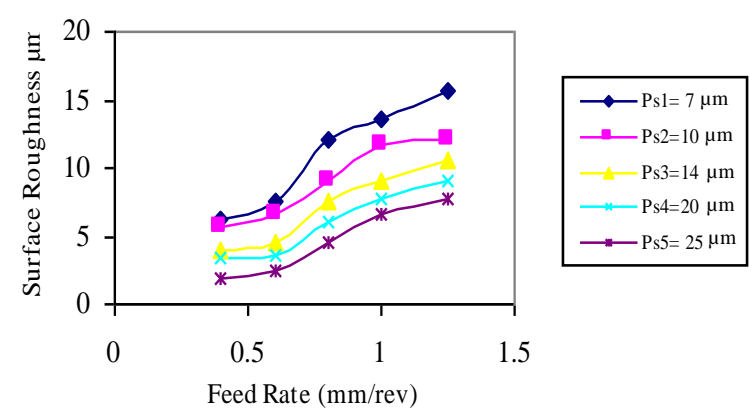

Fig. 23 Feed rate - Ra relations with varying practical size at $(\mathrm{d}=0.25 \mathrm{~mm}, \mathrm{Vf}=5 \%$ and cutting speed $=$ 28rpm)

\subsection{Effect of Volume Fraction on the Resultant Surface Roughness}

Figure 24 shows the influence of volume fractions with different depths of cut values on the resultant surface roughness $(\mathrm{Ra})$ for the machined parts of Al $1050 / \mathrm{SiCp}$. In these experiments, the particle size is equal $7.0 \mu \mathrm{m}$, feed rate $0.4 \mathrm{~mm} / \mathrm{rev}$, and cutting speed $28 \mathrm{rpm}$.

From this figure, it can be seen that, as the volume fraction of reinforcement is increase the resultant surface roughness $(\mathrm{Ra})$ increase for all values of depth of cut. At low levels of Vf (5\%)and $(\mathrm{d}=0.25 \mathrm{~mm})$, the resultant surface is better as compared with any other values. It must be noted that, in this case the particle size and depth of are small also. The bad surface in these results is due to the increase in both volume fraction and depth of cut. The increase of volume fraction leads to increase of particles number. This increase the friction between the cutting edge and particles at the machined surfaces. Also, the increase of friction leads to increase of defects on the resultant surface, such as, grooves and scratches induced by the $\mathrm{SiC}$ particles.

Figure 25 shows the relations between volume fraction and the resultant surface roughness $(\mathrm{Ra})$ at different feed rates $(0.4,0.6,0.8,1.0$ and 1.25 $\mathrm{mm} / \mathrm{rev}$ ), with fixed values of particle size $7.0 \mu \mathrm{m}$, depth of cut $0.25 \mathrm{~mm}$ and cutting speed $28 \mathrm{rpm}$. From this figure, the surface roughness increases with the increase of volume fraction at all values of feed rate. At the low level of volume fraction and feed rate $(5 \%$ and $0.4 \mathrm{~mm} / \mathrm{rev}$ ), the surface roughness is small as compared with other values of volume fraction and feed rate used in this investigation. Figure 26 shows the influence of the volume fraction on surface roughness $(\mathrm{Ra})$ with varying cutting speed (28.45.90.112 and $140 \mathrm{rpm})$ at fixed values of particle size $7.0 \mu \mathrm{m}$ depth of cut $0.25 \mathrm{~mm}$ and feed rate $0.4 \mathrm{~mm} / \mathrm{rev}$.

From this Figure, the increase of volume fraction leads to an increase in surface roughness $(\mathrm{Ra})$ for all values of cutting speed. But at small value of volume fraction (5\%) and large cutting speed (140 rpm), the surface roughness is better as compared with other ratios of volume fraction and all values of cutting speed used in these experiment. The use of large values of volume fraction and small values of cutting speed leads to an increase in the resultant surface roughness $(\mathrm{Ra})$. It is may be due to the increase of particles numbers, and number of particles pulled out specially at low cutting speed, leave behind large bit holes and voids.

In Fig. 27 the relations between volume fraction and surface roughness $(\mathrm{Ra})$ at varying particle size (7.10.14.20 and $25 \mu \mathrm{m})$ are presented at fixed values of feed rate $0.4 \mathrm{~mm} / \mathrm{rev}$, depth of cut $0.25 \mathrm{~mm}$ and cutting speed $28 \mathrm{rpm}$. From this Figure, the surface roughness increases with the increase of volume fraction at different particle size. At 5\% volume fraction and particle size $7.0 \mu \mathrm{m}$ the resultant surface roughness is small as compared with other all volume fraction and particle size. The bad surface is clear at volume fraction ratio $25 \%$ and particle size $25 \mu \mathrm{m}$. It is may be due to the increase in the friction between the edge of cutter and the large number of particles. This lead to high temperature gradients during the cutting which generate residual stresses along with micro and macro cracks on the aluminum matrix and produce bad surface.

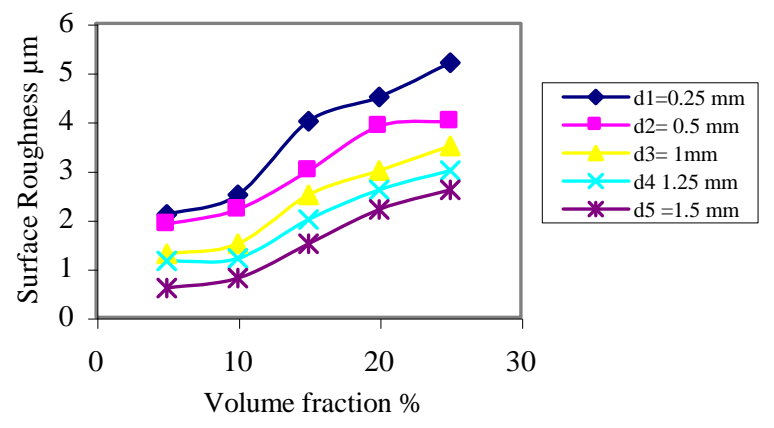

Fig. 24 Fraction ratio - Ra relations with varying depth of cut at $(\mathrm{Ps}=7 \mu \mathrm{m}, \mathrm{f}=0.4 \mathrm{~mm} / \mathrm{rev}$ and cutting speed $=28 \mathrm{rpm})$ 


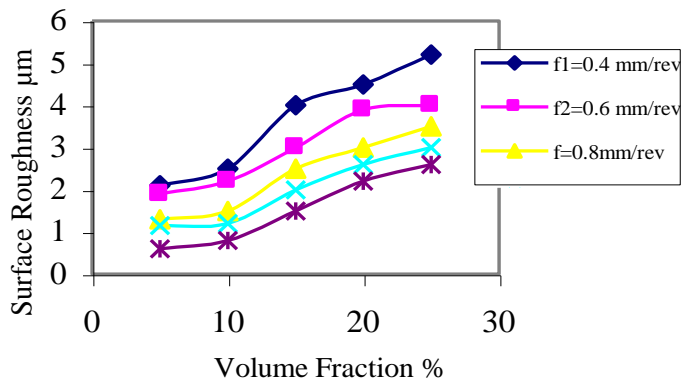

Fig. 25 fraction ratio - Ra relations with varying feed rate at $(\mathrm{Ps}=7 \mu \mathrm{m}, \mathrm{d}=0.25 \mathrm{~mm}$ and cutting speed $=28$ rpm)

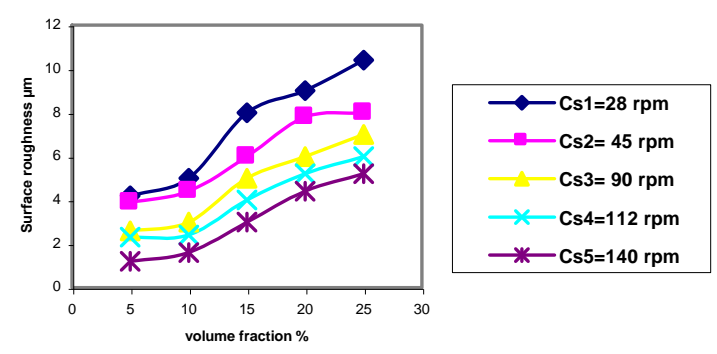

Fig. 26 Fraction ratio-Ra relations with varying cutting speed at $(\mathrm{Ps}=7 \mu \mathrm{m}, \mathrm{d}=0.25 \mathrm{~mm}$ and $\mathrm{f}=0.4$ $\mathrm{mm} / \mathrm{rev}$ )

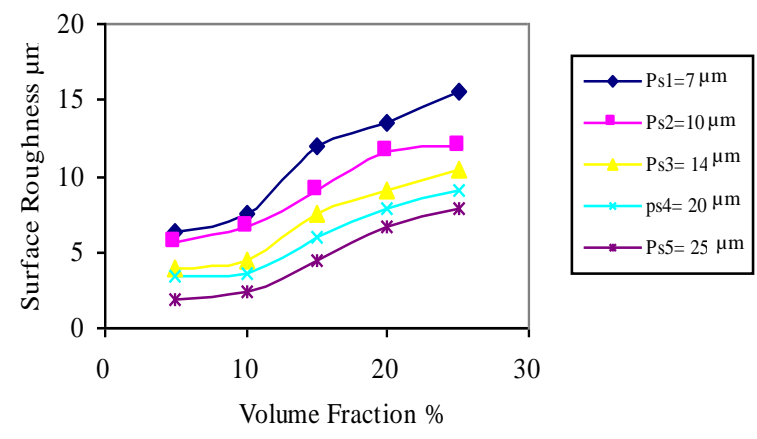

Fig. 27 Fraction ratios - Ra relations with varying particle size at $(\mathrm{f}=0.4 \mathrm{~mm} / \mathrm{rev}, \mathrm{d}=0.25 \mathrm{~mm}$ and cutting speed $=28 \mathrm{rpm}$ )

\subsection{Effect of Particle Size on the Resultant Surface Roughness}

The particle sizes of $\mathrm{SiC}$ particulates used in this work are, 7,10,14,20 and $25 \mu \mathrm{m}$. Fig 28 shows the influence of the particle size on the resultant surface roughness $(\mathrm{Ra})$ at different volume fraction $(5,10,15,20$ and $25 \%)$ of $\mathrm{SiC}$ reinforcement at fixed values of feed rate $0.4 \mathrm{~mm} / \mathrm{rev}$, depth of cut $0.25 \mathrm{~mm}$ and cutting speed $28 \mathrm{rpm}$. From these results, the surface roughness $(\mathrm{Ra})$ increases with the increase of particle size for all values of volume fractions. But at the small values of particle size $7 \mu \mathrm{m}$ and fraction ratio $5 \%$, surface roughness value is small as compared with the other values of particle size and volume fraction. The increase of particle size and volume fraction results in an increase in the friction between the edge of cutter and the particles on the machined surface. This leads to deformation on the surface finish as mentioned before in the previous parts.

In Fig 29 the relation between the particle size and surface roughness $(\mathrm{Ra})$ at varying cutting speeds $(28,45,90,112$ and 140rpm) with fixed values of feed rate $0.4 \mathrm{~mm} / \mathrm{rev}$, depth of cut $0.25 \mathrm{~mm}$ and volume fraction $5 \%$.

From this figure, it is clear that, the surface roughness increases with the increase of particle size for all values of cutting speed .At the small value of particle size $(7 \mu \mathrm{m})$ and cutting speed (140rpm), the surface roughness is better as compared with other values of the parameters used in this experiment. At low cutting speed and large volume fraction ratio, the surface roughness is very bad .It is may be due to the increase of hard particles and respectively the increase of the friction between the edge of cutting tool and the machined surface. As mentioned before, this leads to various types of defects which are shown in the resultant surface.

Figure 30 shows the relation between the particle size and surface roughness $(\mathrm{Ra})$ with varying depth of cut $(0.25,0.51 .5,1.25 \mathrm{and} 1.5 \mathrm{~mm})$ at fixed values of feed rate $0.4 \mathrm{~mm} / \mathrm{rev}$ volume fraction $5 \%$ and cutting speed 28rpm. From this Figure it is obvious that, the increase of particle size leads to an increase of surface roughness $(\mathrm{Ra})$ at the different values of depth of cut. The values of ( $\mathrm{Ra})$ are small when the depth of cut is $(0.25 \mathrm{~mm})$ and particle size is equal $(7 \mu \mathrm{m})$.

On the other hand, the increase of particle size and depth of cut to $25 \mu \mathrm{m}$ and $1.5 \mathrm{~mm}$, leads to dramatic increase in the value of surface roughness ( $\mathrm{Ra}$ ) .It is may be due to the increase of hard particles numbers of the $\mathrm{SiC}$ reinforcement and also the increase of chip thickness due to the increase of depth of cut. This causes some defects which affecting the resultant surface of the machined part.

Figure 31 shows the relation between particle size and surface roughness $(\mathrm{Ra})$ with varying feed rate $(0.4,0.6,0.8,1.0$ and $1.25 \mathrm{~mm} / \mathrm{rev}$. $)$ at fixed values of depth of cut $0.25 \mathrm{~mm}$, volume fraction $5 \%$ and cutting speed $28 \mathrm{rpm}$.

From this figure, it is clear that, the particle size and feed rate are play a vital role in the resultant surface roughness $(\mathrm{Ra})$. The increase of particle size leads to an increase of surface roughness $(\mathrm{Ra})$ for all values of feed rate, particle size and feed rate, $(7.0 \mu \mathrm{m}$ 
and $0.4 \mathrm{~mm} / \mathrm{rev}$ ). The surface roughness is better as compared with other values of particle size and feed rate .The surface roughness is very bad at the large values of particle size and feed rate. The increase of particle size and feed rate, lead to increase in friction between the edge of cutter and the $\mathrm{SiC}$ reinforcement. So, a little number of particles may be pulled out and the matrix may be tearing also. This lead to increase of $\mathrm{Ra}$ for the machined surface.

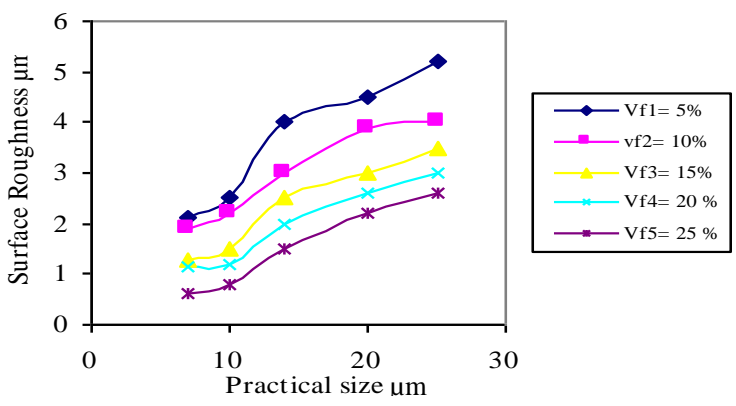

Fig. 28 Particle size-Ra relations with varying fraction ratio at $(\mathrm{d}=0.25 \mathrm{~mm}, \mathrm{f}=0.4 \mathrm{~mm} / \mathrm{rev}$ and cutting speed $=28 \mathrm{rpm}$ )

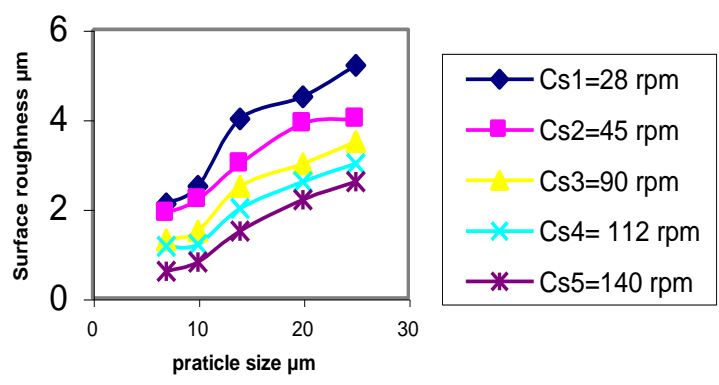

Fig. 29 Particle size-Ra relations with varying cutting speed at $(\mathrm{f}=0.4 \mathrm{~mm} / \mathrm{rev}, \mathrm{d}=0.25 \mathrm{~mm}$ and $\mathrm{Vf}=5 \%$ )

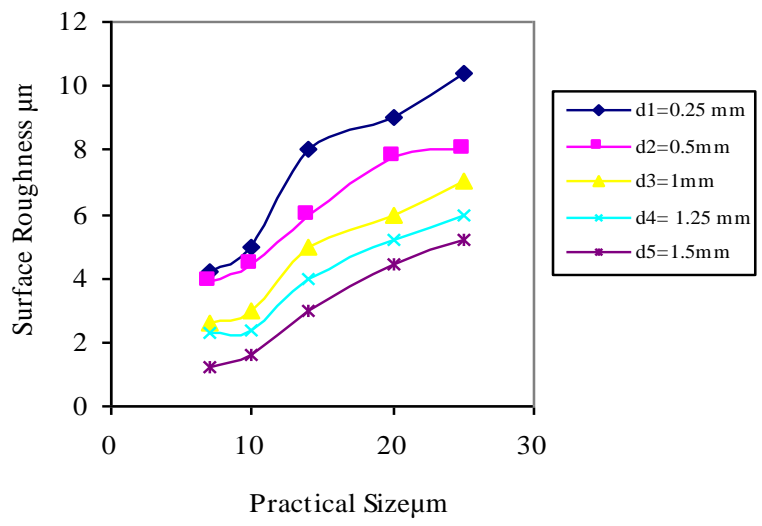

Fig. 30 Particle size - Ra relations with varying depth of cut at $(\mathrm{f}=0.4 \mathrm{~mm} / \mathrm{rev}, \mathrm{Vf}=5 \%$ and cutting speed $=28 \mathrm{rpm}$ )

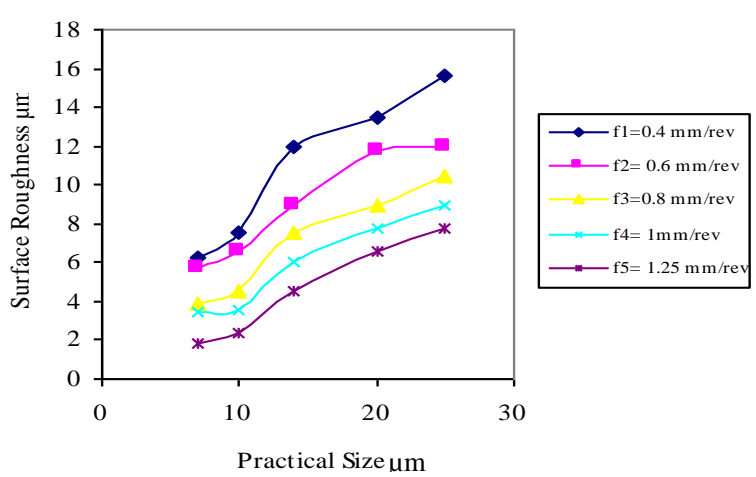

Fig. 31 Particle size -Ra relations with varying feed rate at $(\mathrm{d}=0.25 \mathrm{~mm}, \mathrm{Vf}=5 \%$ and cutting speed $=28$ rpm)

\section{CONCLUSIONS}

The surface roughness model has been developed to correlate five important machining parameters in machining of Al 1050/SiCp MMCs. The rotatable central composite is used for the experimental design. The five parameters are; cutting speed, depth of cut, feed rate, volume fraction and particle size of $\mathrm{SiC}$ reinforcement. May be that is the first time these parameters are studied together. The effect of these parameters on the machined part surface roughness has been analyzed based on the developed mathematical model. Form this work; it can be concluded that;

1. The surface roughness $(\mathrm{Ra})$ decreases with the increase of cutting speed up to $140 \mathrm{rpm}$.

2. The surface roughness $(\mathrm{Ra})$ increases with the increase of depth of cut up to $1.5 \mathrm{~mm}$.

3. The surface roughness $(\mathrm{Ra})$ increases with the increase of feed rate up to $1.25 \mathrm{~mm} / \mathrm{rev}$.

4. The surface roughness $(\mathrm{Ra})$ increases with the increase of fraction ratio up to $25 \%$.

5. The surface roughness $(\mathrm{Ra})$ increases with the increase of practical size of $\mathrm{SiC}$ particles up to $25 \mu \mathrm{m}$.

6. The use of high cutting speed (140 rpm ), depth of cut $0.25 \mathrm{~mm}$, feed rate $(0.4) \mathrm{mm} / \mathrm{rev}$, volume fraction $5 \%$ and practical size $(7.0 \mu \mathrm{m})$ gives a good surface roughness ( $\mathrm{Ra}$ ) as compared with other values of parameters used this work.

7. The experimental results and the predicted values of ( $\mathrm{Ra}$ ) by using the developed model are indicate a good correlation.

8. The procedure followed in this work can be used to predict the surface roughness $(\mathrm{Ra})$ for milling Al $1050 / \mathrm{SiCp} \mathrm{MMCs}$ within the ranges of studied parameters. 


\section{REFERENCES}

[1] B.Manna, Bhatta. Charayya, "A study of machinability of AL/SiC MMC,"J. Mater. Process Technol, (2003). (140). 711-716.

[2] Henri Paris, G. P., R. Mayer," Surface shape prediction in high speed milling," Int. J. Mach. Tool \& Manuf, (2004). (44). 1567- 1576.

[3] P. G. Benardos, G.C. Vosniakos, "Predicting surface roughness in machining: a review," Int. j .Mach. Tools Manuf ,(2003). (43).833-844.

[4] Yanming Quan, Bangyan Ye, "The effect of machining on the surface properties of $\mathrm{SiC} / \mathrm{Al}$ composites," J. Mater. Process Technol, (2003), (138), 464-467.

[5] Y. H. Tsai, J .C. Chen, S. J. Lou, "In process recognition system based on neural networks in end milling cutting operation," Int. J. Mach. Tool. Manuf. (1999). (4). 583-605.

[6] D.k Back , T. J. Ko ,H, S. Kim ," Optimization of feed rate in a face milling operation using surface roughness model," Int .J. Mach. Tool .Manuf. 2001.(41).451-462.

[7] H. Öktem, T. Erzurumlu, M . CÖl. "A study of Taguchi optimization method for surface roughness in finish milling of mold surface ,'Int . J. adv ., Manuf . Technol .(2006) .(28). 694700).

[8] Oguz Colak, Chit Kurbanoglu, M. Cengiz kayacan,, Milling surface roughness prediction using evolutionary programming methods. J Mater and Design, (2007).(28).577-666.

[9] Tugrul Özel, Yigit Karpat. "Predicative modeling of surface roughness and tool wear in hard turning using regression and neural networks," Int J. Mach .tools. Manuf ,(2005)(45).467-479.

[10]Kromunis, A., Krizbergs, J, “3D surface roughness prediction technique in end milling using regression analysis," $6^{\text {th }}$ inter DAAAN Baltic conf., Indust. Engy., 24-26 April (2008), Tallinn, Estonia.

[11]M.A. Dabnum, M.S.J. Hashmi, M.A. El-Baradie, "Surface roughness prediction model by design of experiments for turning machinable glass ceramic (Macor)," J, Mater Process Technol, (2005), (164), 1289- 1293.

[12] C.F. Cheung, K.C. Chan, W.B., Lee, "Surface characterization in ultra precision machining of $\mathrm{AL} / \mathrm{SiC}$ metal matrix composites using data dependent systems analysis," J. Mater Process. Technol, (2003). (140). 141. 146.

[13]F. Dwenin, M. Al-Jarrah, H. All-Wedyan, "Fuzzy surface roughness modeling of CNC down milling of alumic 79," J. Mater. Process .Technol ,(2003). (133).266-275.

[14] Sai wb, salah nb, lebrun JL,' Influence of machining by finishing milling on surface characteristics ," int . J . Mach. Manuf. (2001). (41). 443-450.

[15]Feng cx , Wang x. " Development of empirical models for surface roughness in finish turning," Int .J. Adv. Manuf. Technol .2002). (20) .348356.

[16] Ghani AJ . C. Al, H. HH," Applications of Taguchi method in the optimization of end milling parameters. "J. Mater. Process. Technol, 2004, , (145), 84-92.

[17]Kopa J . Bahor m, Sokovic M ." Optimal machining parameters for achieving the desired surface roughness in fine turning of old preformed steel workpieces ." Ont. J .Mach. Tools Manuuf., (2002) .(42) .707-716.

[18] B.G.Bonardos, G. C. Vosnsiakors," Prediction of surface roughness in $\mathrm{CNC}$ face milling using neural networks and Taguch's design experiments," Rob. And Computer Integrated Manuf. (2002).(18). 343-354.

[19] Julie Z. Zhang, Joseph C. Chen , E. Daniel Jirby .," surface roughness optimization in an end milling operation using the Taguchi design method," J. Mater process Technol, (2007). (184).233-239.

[20] Shibendu S, Roy." Design of genetic fuzzy expert system for predicting surface finish in ultra precision diamond turning of metal matrix composite ,'J. Mater Process Technol .(2006). (173).337- 344 . 